\title{
Developing a Software Tool to Estimate Food Transportation Carbon Emissions
}

\author{
Breuklyn Opp ${ }^{1} \&$ Kurt A. Rosentrater ${ }^{1}$ \\ ${ }^{1}$ Department of Agricultural and Biosystems Engineering, Iowa State University, Ames, Iowa, USA \\ Correspondence: Kurt A. Rosentrater, Department of Agricultural and Biosystems Engineering, Iowa State \\ University, Ames, Iowa, USA. E-mail: karosent@ iastate.edu
}

Received: May 7, 2020

doi:10.5539/jfr.v9n4p10

\author{
Accepted: June 6, $2020 \quad$ Online Published: June 13, 2020 \\ URL: https://doi.org/10.5539/jfr.v9n4p10
}

\begin{abstract}
Food transportation is an increasingly important consideration to total food sustainability in a rapidly globalizing world. To maintain the efficiency of regionalized production, food travels great distances to the consumer's plate. While this long-distance sourcing is often more sustainable from a production standpoint, the routes from origin to consumer are frequently unoptimized. To reduce emissions due to transportation, many have tried to limit the miles travelled by food items. However, the mode of travel is an equally important factor. Different modes produce vastly different emissions over equivalent distances. To effectively model these routes, a set of transportation emissions estimation tools has been created. This program uses an Excel interface to allow users to input key factors (like cargo mass, origin, and destination) and experiment with different modes and routes of travel to find the optimal transportation system for their application. This program may be used to analyze or improve the total life cycle analysis of a variety of products. In a case of the comparison of transportation modes, a salmon transportation route from the Faroe Islands (America's $2^{\text {nd }}$ largest source of imported fresh salmon) to Richmond, VA, USA, resulted in a roughly $98 \%$ reduction of emissions when shipped via sea rather than flown. In a case of transportation optimization, the reciprocal trade of beef between Costa Rica and the United States was found to result in at least $158,000 \mathrm{~kg}$ of $\mathrm{CO}_{2 \mathrm{eq}}$ annually. These cases (and others) show the great need for better route optimization in food transportation systems.
\end{abstract}

Keywords: food, food miles, greenhouse gases, global warming potential, trucking, shipping, transportation

\section{Introduction}

Urbanization and consumer demand for non-local products has made transportation an increasingly vital section of the food economy. While these imports and exports have resulted in regional specialization and increased the dietary options of consumers, the globalization of the food economy has greatly changed the environmental impact of food systems. The current greenhouse gas emission trajectory is estimated to reach over 80 gigatons of $\mathrm{CO}_{2 \mathrm{eq}}$ by 2050 (Mooney, 2015). Comparatively, the widely accepted climate change budget issued by the UN Environment Program would limit carbon emissions to 54 gigatons of $\mathrm{CO}_{2 e q}$ by 2030 (Mooney, 2015). However, even the 54 gigaton limit will result in climbing world temperatures. To reduce these effects, emissions must be limited from every source, including transportation. According to the EPA, the transportation sector produced 14\% of global carbon emissions in 2010 (EPA, 2018). Out of this problem, a new buzz phrase arose - "food miles". This term refers to the distance a food item travels from production to consumer, often with a focus on sustainability. Although local sourcing has managed to cut some of the transportation emissions, the trend is mostly practiced at convenience. Many types of food are expensive and difficult to grow and maintain in an unsuitable climate. When transportation is essential for the products that an area relies upon - but does not produce - the environmental impact of lengthy travel routes is not always considered or strategized. To remedy this, travel emissions can be modeled to find the best feasible route with the lowest emissions.

While the focus of transportation optimization is often focused on distance, there are many other factors that affect the sustainability of transportation systems. A truck, train, plane, and ship used to transport the same cargo over the same distance would result in vastly different emissions. Of these, air travel is the most environmentally burdensome mode of travel. In the food sector particularly, much of the food that is flown is due to consumer demands for fresh products. Truck travel is the next most impactful option for transportation modes. This, however, is a very popular mode of transportation due to the low cost and lack of extra required infrastructure. 
In 2015, shipment by HDV (heavy-duty vehicle) accounted for about $66 \%$ of total USA freight shipment by weight. Rail shipments accounted for about $9.1 \%$ of this shipped weight. By 2045 , truck shipment is expected to grow in share of freight transportation by about $2 \%$ (while rail is expected to shrink by about $1.5 \%$ ). Water shipment is expected to drop from $3.4 \%$ to $2.9 \%$ of total domestic shipments, while air freight change was negligible. This trend indicates a general increase in emissions, even if the total food shipped remains the same. This brings an important topic to the table - if shipping routes were altered to allow for more sustainable modes of transportation, could the environmental effects of shipping more food in the future be mitigated or reduced?

While there are many other factors that contribute to food sustainability, food sourcing results in an estimate of $9 \%$ of the life cycle emissions for food products (EPA, 2018). Depending on the route taken, this proportion can vary from $<1 \%$ in local produce to about $90 \%$ in fresh-flown seafood (Farmery et al., 2015). This variety is what makes the analysis of routes vital to the environmental performance of transportation systems. Changing the origin of the food or the mode of transportation to find a more optimal pathway can play a critical role in reducing total product emissions.

In response to the environmental issues associated with the food industry, the three tools presented here are intended to model transportation routes. These tools present the opportunity for the user to use various input formats in an Excel workbook interface and then receive a $\mathrm{CO}_{2 \mathrm{eq}}$ estimate for a given route. The greenhouse gas emission estimate was calculated for each chosen path of travel based on the mode of travel, mass of cargo, and distance. These modeled routes can be used to examine the sustainability of food sourcing and transportation. Through better analysis and modeling of these systems, engineers and consumers alike can make more environmentally conscious decisions in transportation systems, resulting in an altogether more sustainable society.

\section{Methodology}

\subsection{Data}

The modeling of the transportation emissions requires emissions factors that are specific to common vehicle groupings. The software tools use estimates calculated from the Network for Transport Measures (NTM) to rate the emissions for each mode of transportation. To ensure simplicity for the user, the data and figures used were estimates for the most typical travel scenarios. The graph in figure 1 shows the emission ratings (per tonne-kilometer) for each mode of travel ("NTMCalc 4.0," n.d.). The chart (fig. 2) was used for the mode decision logic displayed on the initial page of the program.

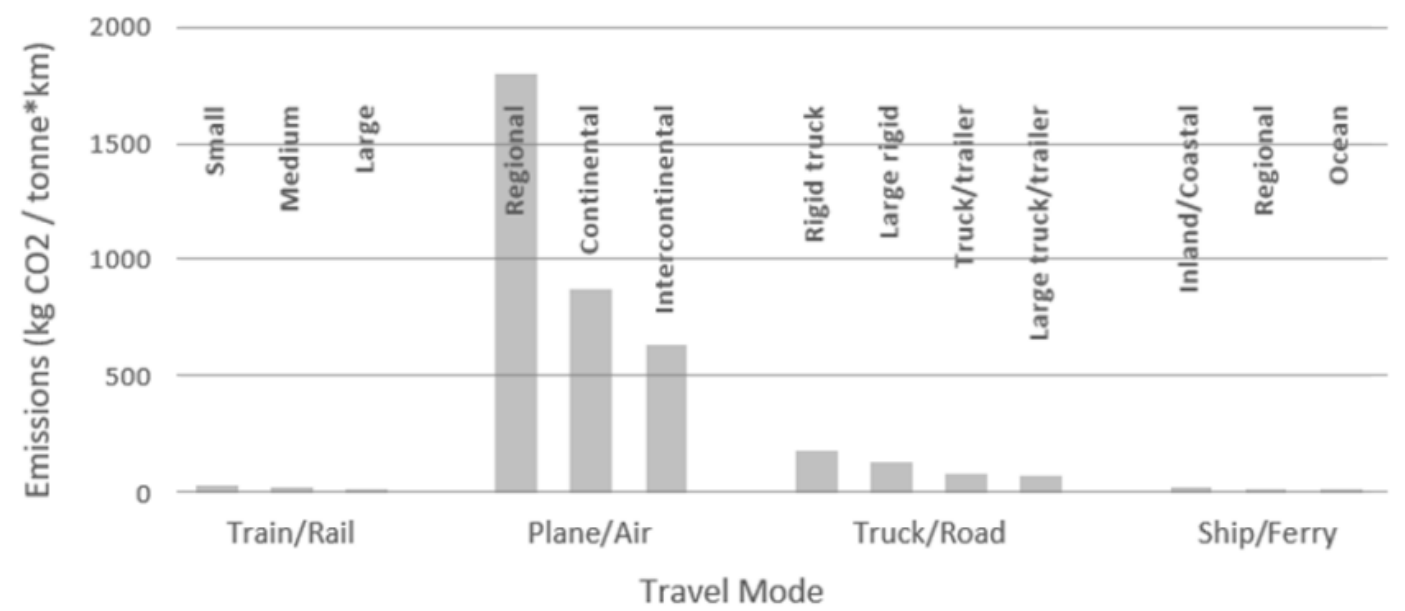

Figure 1. Emission factors for a variety of transportation modes 


\begin{tabular}{|c|c|c|}
\hline Emissions & & Usage range \\
\hline Small cargo train & $35.28\left(\mathrm{~g} \mathrm{CO}_{2 \mathrm{e}}\right) /($ tonne*km) & Cargo mass $<90 t$ \\
\hline Medium cargo train & $22.95\left(\mathrm{~g} \mathrm{CO}_{2 \mathrm{e}}\right) /($ tonne*km) & $90 \mathrm{t} \leq$ Cargo Mass $<110 \mathrm{t}$ \\
\hline Large cargo train & $17.85\left(\mathrm{~g} \mathrm{CO}_{2 \mathrm{e}}\right) /($ tonne*km) & $110 \mathrm{t} \leq$ Cargo mass $<120 \mathrm{t}$ \\
\hline Regional freight aircraft & $1798\left(\mathrm{~g} \mathrm{CO}_{2 \mathrm{e}}\right) /($ tonne*km) & Distance travelled $\leq 2300 \mathrm{~km}$ \\
\hline Continental freight aircraft & $869.3\left(\mathrm{~g} \mathrm{CO}_{2 \mathrm{e}}\right) /($ tonne*km) & $2300 \mathrm{~km}<$ Distance travelled $\leq 6600 \mathrm{~km}$ \\
\hline Intercontinental freight aircraft & $632.4\left(\mathrm{~g} \mathrm{CO}_{2 \mathrm{e}}\right) /($ tonne*km) & $6600 \mathrm{~km} \leq$ Distance travelled \\
\hline Rigid truck & $176.8\left(\mathrm{~g} \mathrm{CO}_{2 \mathrm{e}}\right) /($ tonne*km) & Cargo mass $<7.5 \mathrm{t}$ \\
\hline Large rigid ruck & $129.5\left(\mathrm{~g} \mathrm{CO}_{2 \mathrm{e}}\right) /($ tonne*km) & $7.5 \mathrm{t} \leq$ Cargo Mass $<20 \mathrm{t}$ \\
\hline Truck and trailer & $82.52\left(\mathrm{~g} \mathrm{CO}_{2 \mathrm{e}}\right) /($ tonne*km) & $20 \mathrm{t} \leq$ Cargo Mass $<34 \mathrm{t}$ \\
\hline Large truck and trailer & $71.58\left(\mathrm{~g} \mathrm{CO}_{2 \mathrm{e}}\right) /($ tonne*km) & $34 \mathrm{t} \leq$ Cargo Mass $<60 \mathrm{t}$ \\
\hline Inland/Coastal cargo ship & $21.06\left(\mathrm{~g} \mathrm{CO}_{2 \mathrm{e}}\right) /($ tonne*km) & Distance travelled $\leq 2000 \mathrm{~km}$ \\
\hline Regional cargo ship & $15.732\left(\mathrm{~g} \mathrm{CO}_{2 \mathrm{e}}\right) /($ tonne*km) & $2000 \mathrm{~km}<$ Distance travelled $\leq 4000 \mathrm{~km}$ \\
\hline Ocean cargo ship & $12.41\left(\mathrm{~g} \mathrm{CO}_{2 \mathrm{e}}\right) /($ tonne*km) & $4000 \mathrm{~km} \leq$ Distance travelled \\
\hline
\end{tabular}

Figure 2. Emission factors for transportation mode types (as used in the software tools). These are approximate estimates and the number of figures used for the mode ratings does not indicate high certainty. These data were used for calculations to give general carbon emission estimates

The data in figures 1 and 2 were compiled by the NTM from different suitable databases for each mode. The "road" transportation data was collected from the 2010 update of the Handbook of Emissions Factors for Road Transportation (or HBEFA 3.1). This handbook uses the Passenger Car and Heavy-Duty Emission Model, which uses engine mapping to dynamically monitor the emissions exiting the vehicle and compares these data to the actual power of the engine (Hausberger et al., 2009). By collecting data from a multitude of common on-road vehicles of the same hauling capacity, the HBEFA developed a set of values used to estimate the emissions based on vehicle load and distance.

"Rail"-type emission ratings were collected using similar methodology. The power required to propel a train carrying various cargo weights in common environments was compared to the emissions discharge mapping of the train to gather a multitude of data points. The data was then compiled to form a "typical" emissions rating (using average load percentages and average topographical condition factors) for the three train categories ("NTMCalc 4.0," n.d.). For the purpose of this program (which is expected to be used for loads that are less than 120 tons), it is most logical to base the type of train used - and the resultant emissions factor - on the mass loaded into an individual rail car. While the NTM was responsible for the organization of the data, the International Union of Railways (or UIC) collected the data ("NTMCalc 4.0," n.d.).

Data for waterway modes was collected in a less direct method. Since the resistance acting on the vessel has far more variation (from the effects of both load weight and buoyancy), the power simulation techniques used in the ground transportation methods was not as applicable to the calculation of water transportation coefficients. Instead, the International Maritime Organization (IMO) released statistics relating the required energy consumption of the ship to its type and deadweight ("NTMCalc 4.0," n.d.). The related emissions were then calculated from the fuel consumption required to provide that power. For the final rating, a coefficient of resistance was applied to reflect the effects of water drag on the ship (Cooper \& Gustafsson, 2004).

The air data collection methods were much more variant than those of the other travel modes. For each general "type" of aircraft, the fuel consumption for a typical load per unit distance was calculated. The fuel consumption (with fuel type assumed to be Jet A-1) was related to a fuel efficiency factor that determines the carbon emissions of this type, much like the ship method ("NTMCalc 4.0," n.d.). The typical load mass used to find the total fuel usage was then taken as two parts - passenger load mass and cargo load mass. Since few planes are solely freight planes, the NTM assumes that the aircrafts used for transportation also carry humans. This dual functionality, the NTM estimates, reduces the total carbon output per unit of flighted cargo mass by $30 \%$ ("NTMCalc 4.0," n.d.). The aircrafts in the program were grouped by travel distance due to both typical aircraft size and flight pattern at these distances. These figures were collected from the International Civil Aviation Organization and compiled by the NTM. The carbon output per unit cargo mass is, like in all the other modes 
discussed here, usually reduced by greater total vehicle size. Unlike the other modes, air travel emissions are very dependent on range, as the take-off and landing flight pattern result in added emissions for the total flight. To account for this, a variable emissions factor (related to both distance and unit of cargo mass) and a stagnant emissions factor (variable by only cargo mass for take-off and landing patterns) were combined to form a total emissions factor for each major plane range ("NTMCalc 4.0," n.d.).

It must be noted that the emissions factors used in this study are approximate estimates garnered from previous studies, and the number of significant figures used for the mode ratings does not indicate a level of certainty. These data are comprised of averages used only in calculations to give general carbon emission estimates. The emissions output values in the program are rounded to reflect the range of error found amongst these factor estimates and the estimates of other references, but still do not fully reflect possible error from actual transportation routes and variation in vehicle type, maintenance, or efficiency.

\subsection{Program Logic}

The modeling program was an Excel Macro-Enabled Workbook (*.xlsm) containing several macros and developer controls. The software tools run on a series of Visual Basic (VBA) codes. Foundationally, the codes were used to compile three pieces of information - the distance travelled, the mode of travel, and the cargo mass.

The following equation was then used to determine each route's resulting carbon dioxide emissions:

Where:

$$
\text { Em }=\left(\text { dist }_{1} * \text { mrat }_{1} * \text { mass }_{1}\right)+\left(\text { dist }_{2} * \mathrm{~m}_{\text {rat2 }} * \operatorname{mass}_{2}\right)+\ldots\left(\text { dist }_{\mathrm{n}} * \mathrm{~m}_{\mathrm{ratn}} * \operatorname{mass}_{\mathrm{n}}\right)
$$

- $\quad \mathrm{Em}=$ emissions $\left(\mathrm{g} \mathrm{CO}_{2 \mathrm{eq}}\right)$

- $\quad$ dist $=$ distance $(\mathrm{km})$

- $\mathrm{m}_{\mathrm{rat}}=$ mode emissions rating $\left(\left(\mathrm{g} \mathrm{CO}_{2 \mathrm{eq}}\right) /(\right.$ tonne $* \mathrm{~km})$

- $\quad$ mass = cargo mass (tonnes)

- $1,2, \ldots, \mathrm{n}=$ these subscripts denote each sequential route segment

The generic setup of the program includes a single module with master equations that were utilized in each tab as well as a tab-specific code for each tool. The master equations were used to call in information from online resources, and contain equations that were used in multiple tools. This results in a system of four unique sets of code (one for each tool) and one code used to integrate the information into simple output.

Several of the master equations were needed for locational data. This was usually the first data point calculated in the tools as both distance and mass values were required to select ranges for vehicle types. As the mass and mode of transportation were provided by the user, the distance calculation was the first step in this process. The coordinates of a string address were found using data called in from a Google API (Application Programming Interface). With the input of an address, the program can relay the string of words via an internet connection to the Google Maps API (fig. 3). A set of coordinates for the address was then returned. 

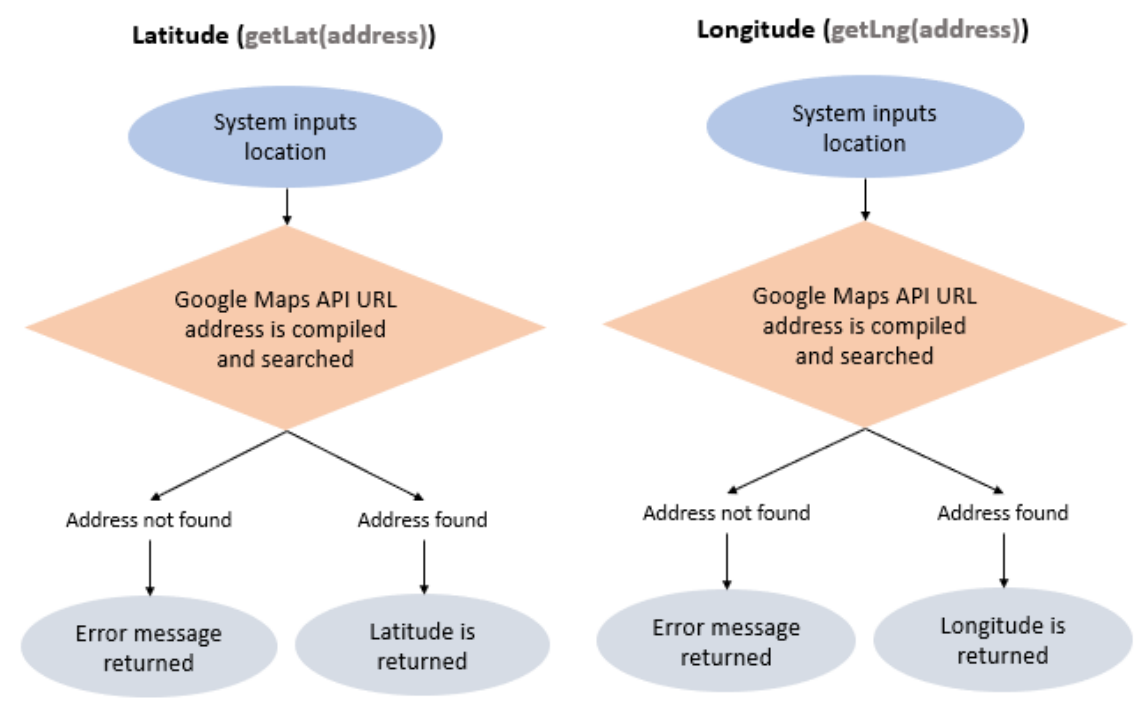

Figure 3. Logic flow of longitude/latitude acquisition

These values were then used in an equation that helps calculate the distance between two points on the globe. For this function, the latitude and longitude of both locations were inputted and run through a Haversine formula, which calculates the "as the crow flies" distance between the points (fig. 4).

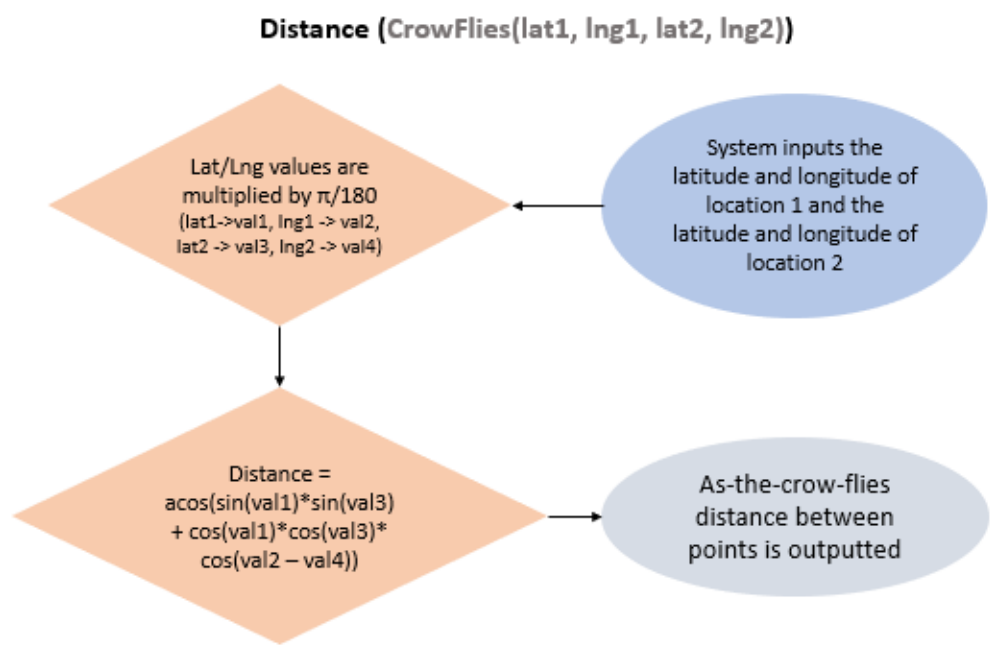

Figure 4. Logic flow of distance calculation

After the distance between points was determined, the three input values - the distance, cargo mass, and mode of transportation - were stored and the most likely mode of transportation was selected based on the usage ranges (the distance travelled or cargo mass) that were entered/selected (fig. 5). For the Plane/Air and Ship/Ferry modes, a distance range determines the rating. For example, if the cargo is traveling $4000 \mathrm{~km}$ directly by air, the most likely mode of travel would be by continental freight aircraft. For the Train/Rail and Truck/Road options, the usage range was based on the cargo mass. Similarly, if the user entered a cargo mass of 25 tonnes for a truck route, the most likely mode form would be a truck and trailer. 


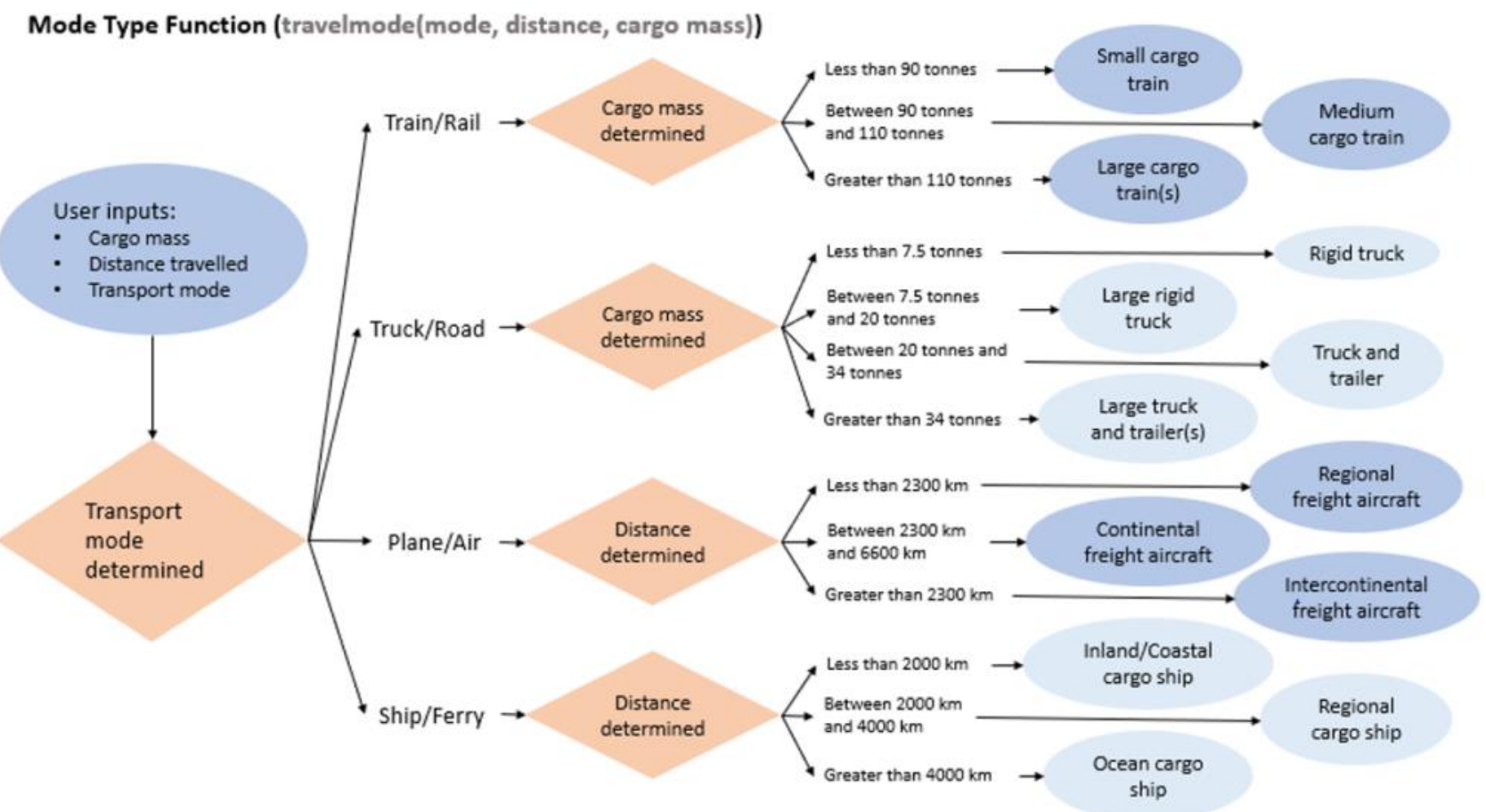

Figure 5. Logic flow of mode type selection

After the type of vehicle used was determined, a function assigns an emissions rating to the mode of travel and uses this emissions rating to calculate total emissions. This emissions value (in $\mathrm{kg} \mathrm{CO}_{2 \mathrm{eq}}$ ) was calculated through the multiplication of the mode emissions rating, mass of the cargo, and distance travelled (fig. 6).

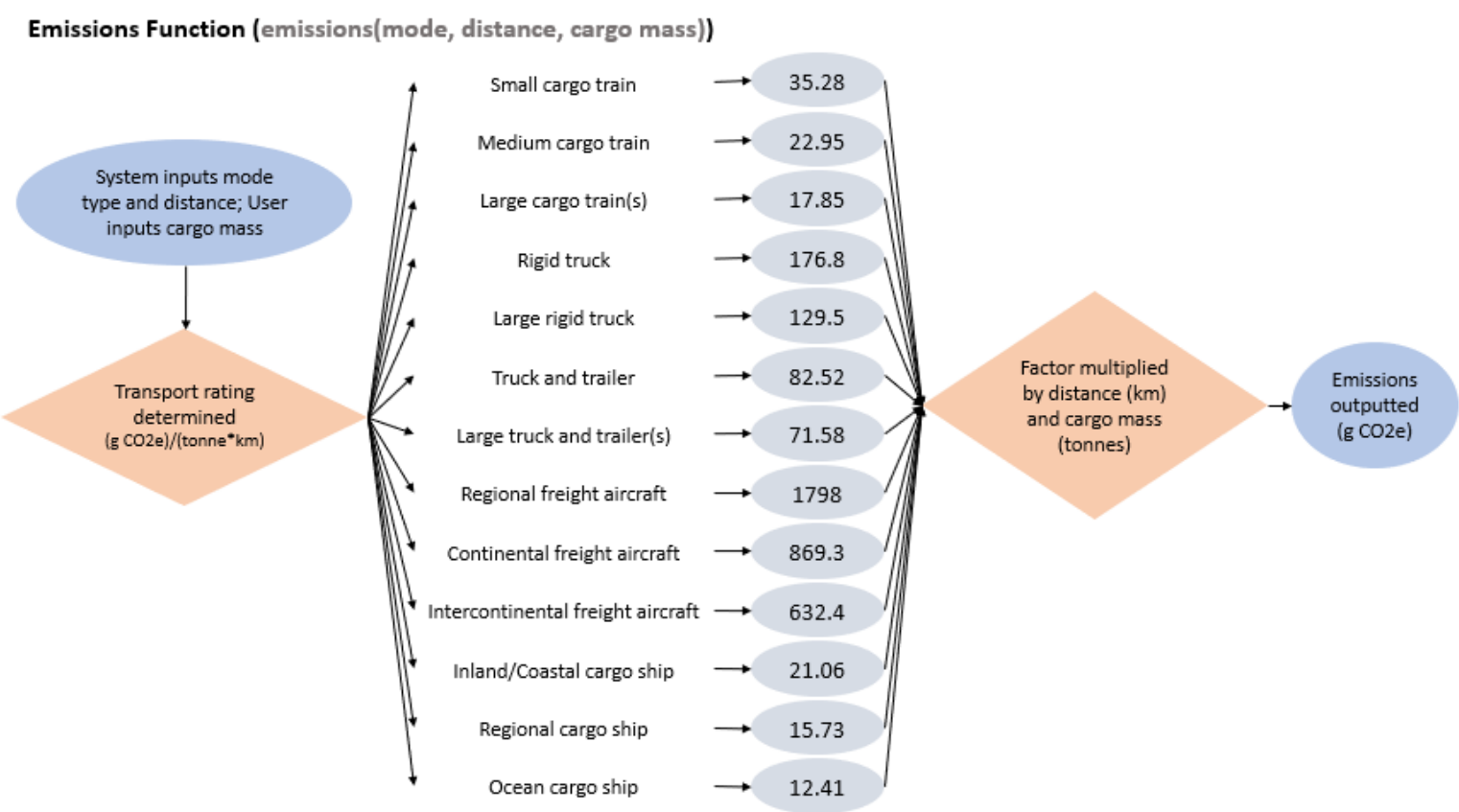

Figure 6. Logic flow of emissions factor determination

The API was also used for error checking in the software tools to prevent the calculation of distance for truck or rail travel over major bodies of water. For this function, Google Maps treats the two input addresses as a request 
for road-travel directions between the two points. If road travel was not possible, a geographical barrier (like an ocean) was expected. Figure 7 shows this process. Google's directions, however, will not provide routes across some national borders (such as that between China and any neighboring country). In this case, the error checking has been overridden with keyed-in edits. For those that receive unwanted or unwarranted error reports, the function was optional. Each tool has a regular function button as well as an override button to opt out of such features.

Error-checking (getDistance(address1, address 2))

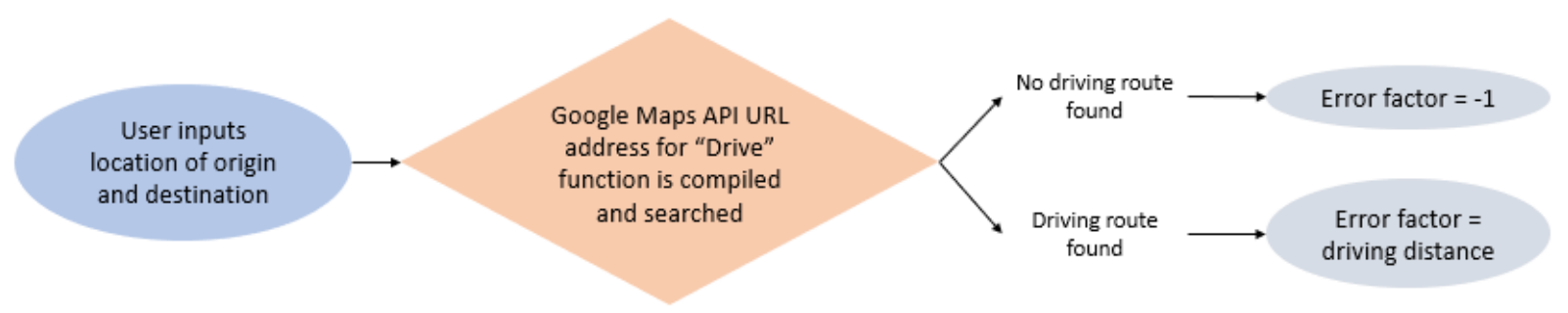

Figure 7. Logic flow of error-checking

The tab-specific codes help integrate the master formulas into different scenarios and formats. This allows for the software tools to have a resettable structure to clear any edits or entered information. This also enables the mapping of entered locations on the $2^{\text {nd }}$ and $3^{\text {rd }}$ tools. Most of the generic calculations were used in the tab-specific sections to ensure that the cell placement of the inputs and results were accurate.

The third tool also contains unique code to assist in finding potential ports. This function "suggests" ports from the most commonly used ports in the world (the top 100 airports and top 150 ship ports). The porting function integrates the locational codes from the module and some tab-specific port information to find ports that were accessible by road or rail, determined by the error tests provided by the distance Google API (fig. 8). By limiting ports to those that were drivable, the tool more reliably models a likely overseas transportation sequence of ground-overseas-ground travel.

Port function (PortList(address1, address 2))

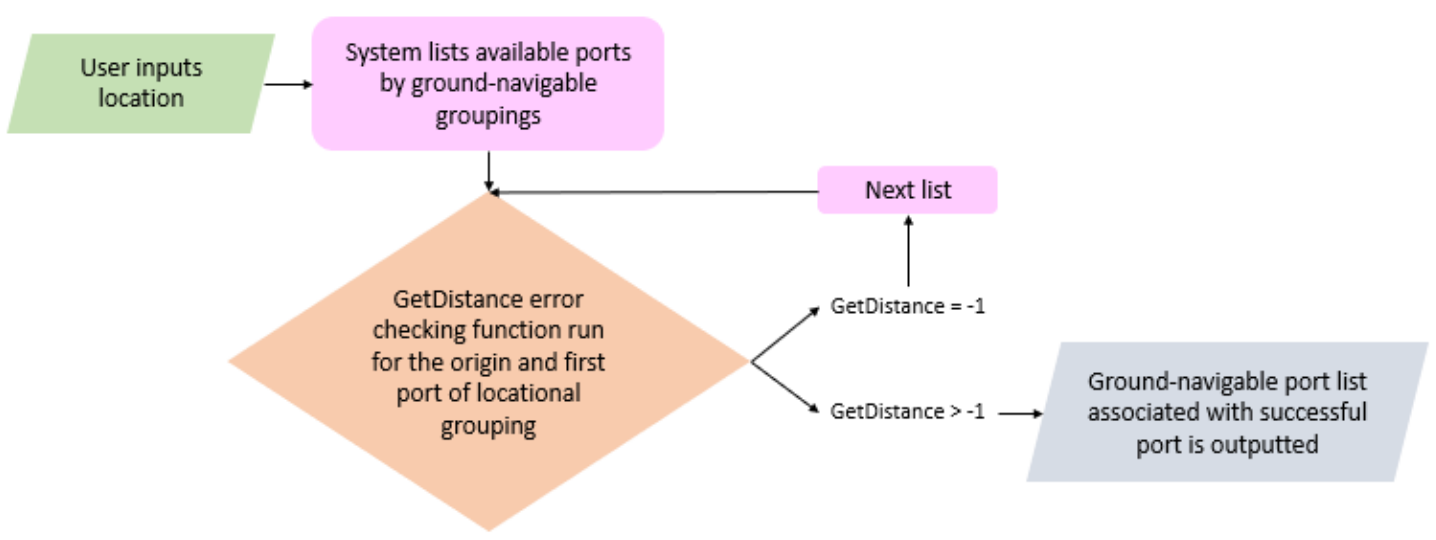

Figure 8. Logic flow of port list determination

The port-finding capabilities of the third software tool also allow for another unique feature - an optimization function. This function helps further suggest low emissions transportation routes given an origin and destination (fig. 9). Due to the great difference between road and rail emissions factors, the ground transportation sections were assumed to be via rail for lowest emissions estimation. While this assumption was not made in the overseas portion, it was extremely likely that this portion of the transportation will be via ship due to the same reasoning. 


\section{Optimization (lowEmiss(address1, address 2))}

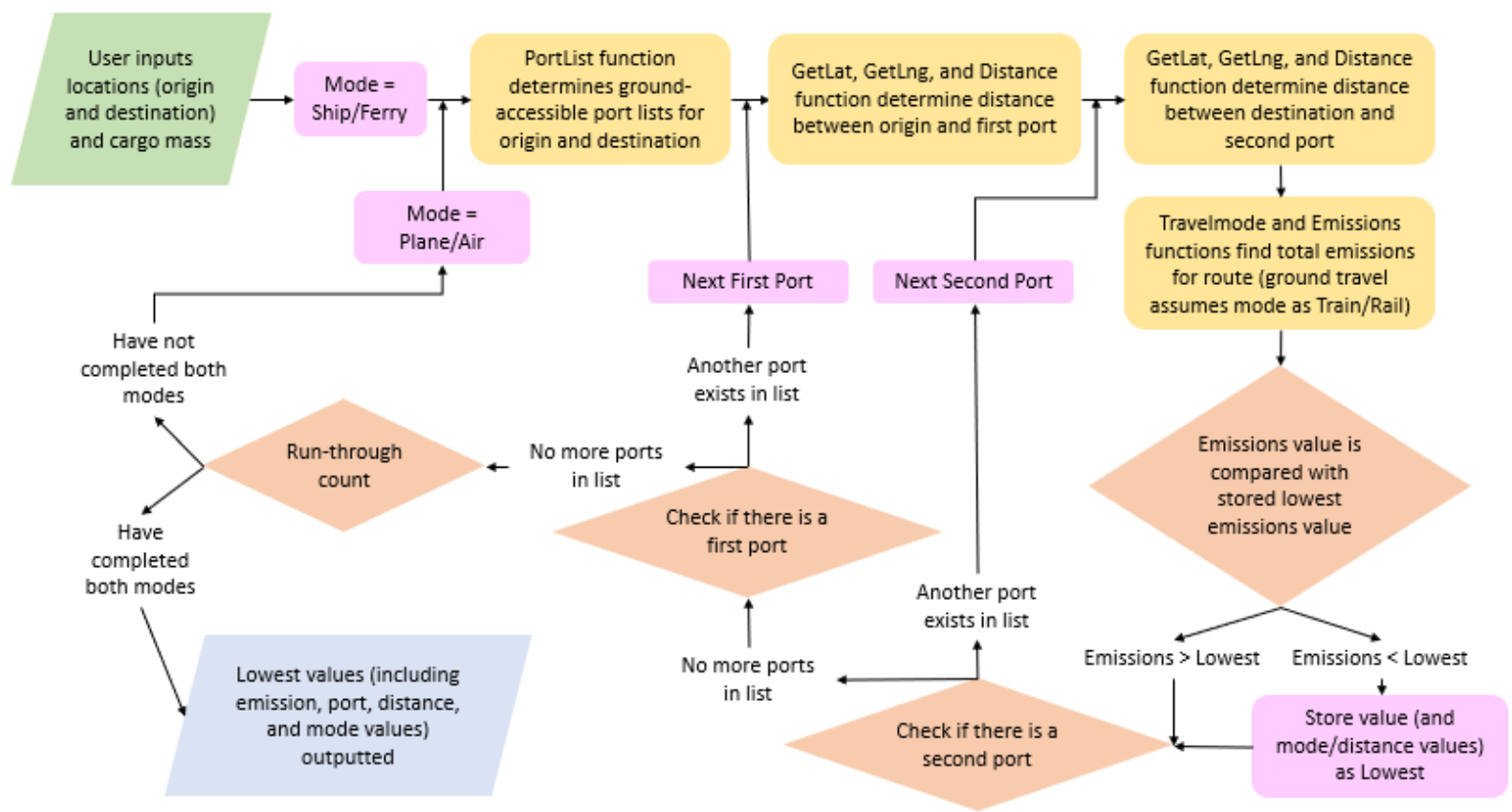

Figure 9. Optimization logic flow

\section{Software Overview}

\subsection{Export Estimations}

The export estimations tab produces a visualization of the production of food groups by region. The user may select a group from the drop-down list to display dots scaled by the mass of regional exports and the numerical values of the exports. The information may provide insight on likely origins of certain products. The layout of this page is shown in figure 10 .

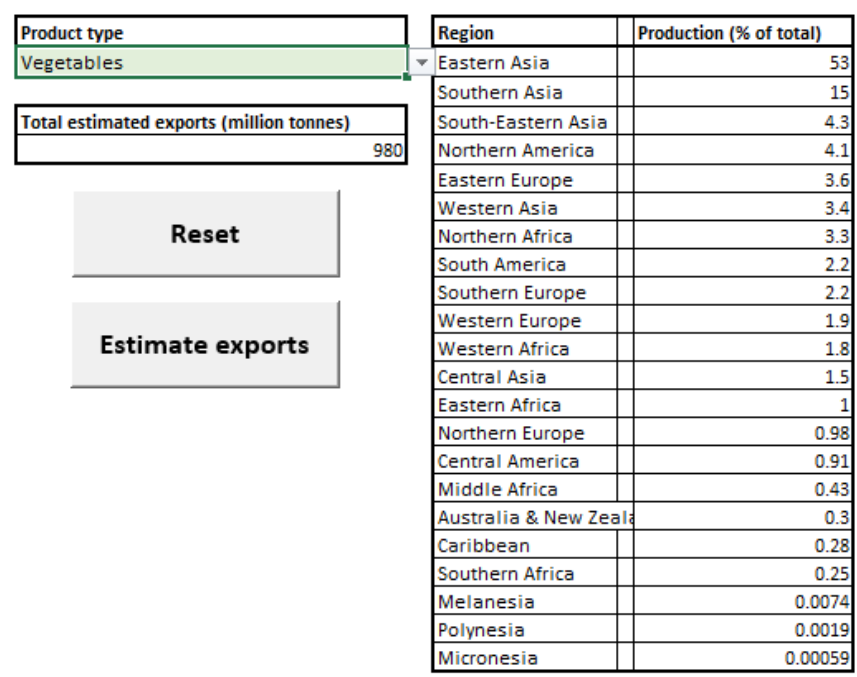

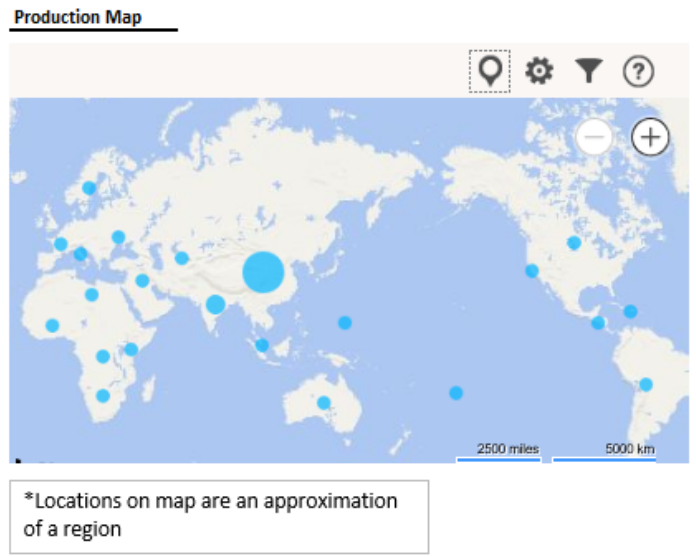

Figure 10. Software layout for export estimations

\subsection{Tool 1}

Tool 1 is noted for its simplicity. The user may enter the total distance travelled, the proportion travelled through each mode, and the mass of the load and the tool will return $\mathrm{CO}_{2 \mathrm{eq}}$ estimates (fig. 11). This tool does not allow 
the user to split the trip into several segments. It also does not allow address inputs or use any distance calculation functions, but still utilizes the "most likely mode of transportation" function for each segment of travel.

\begin{tabular}{|l|r|l|}
\hline Entered information & & \\
\hline Total distance travelled & 3000 & $\mathrm{~km}$ \\
\hline Cargo mass & 50 & tonnes \\
\hline Percent by plane & 25 & $\%$ \\
\hline Percent by train & 25 & $\%$ \\
\hline Percent by ship & 25 & $\%$ \\
\hline Percent by truck & 25 & $\%$ \\
\hline Total distance travelled & 100 & $\%$ \\
\hline
\end{tabular}

\begin{tabular}{|l|l|r|l|l|l|r|l|}
\hline Modes & Probable type of mode & Distance travelled & & & & Carbon emissions (kg CO2e) & \\
\hline Plane/Air & Regional freight aircr & 750 & $\mathrm{~km}$ & & & 67000 & $\mathrm{~kg} \mathrm{CO} 2 \mathrm{e}$ \\
\hline Train/Rail & Small cargo train & 750 & $\mathrm{~km}$ & & & 1300 & $\mathrm{~kg} \mathrm{CO} e \mathrm{e}$ \\
\hline Ship/Ferry & Inland/Coastal cargo & 750 & $\mathrm{~km}$ & & & 790 & $\mathrm{~kg} \mathrm{CO} \mathrm{e}$ \\
\hline Truck/Road & Large truck(s) and trai & 750 & $\mathrm{~km}$ & & & 2700 & $\mathrm{~kg} \mathrm{CO} 2 \mathrm{e}$ \\
\hline
\end{tabular}

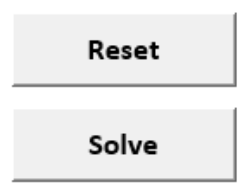

Figure 11. Software Tool 1 layout

\subsection{Tool 2}

Tool 2 is the most versatile portion of the program. This section allows inputs of checkpoint addresses, masses of cargo, and modes of transportation. The distance travelled and carbon emissions were displayed for each section of travel and summed for a total $\mathrm{CO}_{2 \mathrm{eq}}$ estimate. A map was also provided to visualize the route taken. This layout is shown in figure 12. All distances were measured "as the crow flies," so the map allows the user to see any geographical issues in the route taken. As in the $1^{\text {st }}$ tool, the modes used were the result of the "most likely mode" function.

\begin{tabular}{|c|c|c|c|c|c|c|}
\hline Reset & & Solve 10 & Override) & Map & & \\
\hline \multicolumn{4}{|l|}{ Entered information } & \multicolumn{3}{|l|}{ Caloulated information } \\
\hline & \begin{tabular}{|l|} 
AddressilLocation \\
\end{tabular} & Mass of Cargo (tonnes) & Mode of Transportation & Most likely transportation form & Distance travelled $(\mathrm{km})$ & Carbon emissions (kg CO2e) \\
\hline \begin{tabular}{|l} 
Origin \\
\end{tabular} & New Youk, NY & 75 & Planelair & Intercontinenctal freight aiccraft & 11000 & 520000 \\
\hline Point 2 & Beijing, China & 50 & Train/Rail & Small cargottain & 5800 & 10000 \\
\hline Point 3 & Mosoon, Russia & 50 & TuckliRoad & Lageetruckss and trailen(s) & 2510 & 9000 \\
\hline Point 4 & Edinburgh, Germany & & & & & \\
\hline \multicolumn{7}{|l|}{ Point 5 } \\
\hline \multicolumn{7}{|l|}{ Point 6} \\
\hline \multicolumn{7}{|l|}{ Point 7} \\
\hline \multicolumn{7}{|l|}{ Point 8} \\
\hline \multicolumn{7}{|l|}{ Point 9} \\
\hline \begin{tabular}{|l|} 
Point 10 \\
\end{tabular} & & & & & & \\
\hline & & & & TOTAL & 19300 & 54000 \\
\hline
\end{tabular}

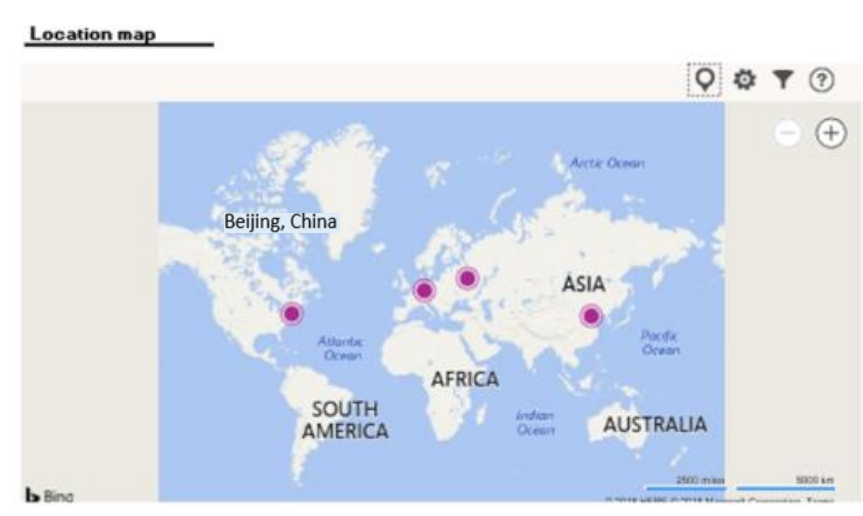

Figure 12. Software Tool 2 layout 


\subsection{Tool 3}

The most restrictive and structured section of the software is Tool 3. The formatting was set up to reflect a common pattern of travel for many goods - a route of ground travel from the origin to a major port, where the product is flown or shipped to another major port, from which the product travels by ground to the destination. This tool prompts the user to enter an origin and destination. The modes of travel were then selected, after which the port locations may be selected from a dropdown list. Figure 13 shows this layout. This requires the use of a function that selects two ports accessible by land, one from the origin and one from the destination. The tool then calculates an estimate of emissions for the route. Like Tool 2, the "most likely mode" and mapping functions were also used. Tool 3 was uniquely useful due to its optimization function. The user may opt to only enter in the cargo mass, origin, and destination. This tool can then suggest the lowest-emission route based on the information given.

\begin{tabular}{|l|l|}
\hline Entered information & \\
\hline Location of origin & Ames, IA \\
\hline Location of destination & Beijing, China \\
\hline Cargo mass (tonnes) & \\
\hline
\end{tabular}

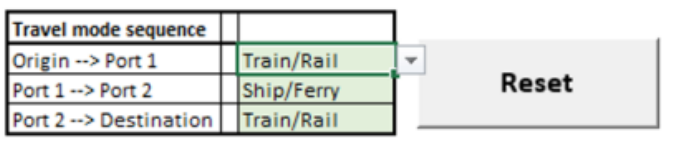

List ports

List ports (override)

\begin{tabular}{|c|c|c|c|c|c|c|}
\hline & Location/Address & Cargo mass (tonnes) & Travel mode & Most likely travel form & Distance travelled $(\mathrm{km})$ & Carbon emissions (kg CO2e) \\
\hline \multirow[t]{2}{*}{ Origin } & Ames, IA & & & & & \\
\hline & & 50 & Small cargo train & & 1240 & 2200 \\
\hline \multicolumn{7}{|l|}{ Port 1} \\
\hline & \multicolumn{2}{|c|}{ South Louisiana, United States } & & & & \\
\hline & & 50 & Ocean cargo ship & & 11600 & 7200 \\
\hline \multicolumn{7}{|l|}{ Port 2} \\
\hline & Tianjin, China & & & & & \\
\hline & & 50 & Small cargo train & & 103 & 180 \\
\hline Destination & Beijing, China & & & & & \\
\hline & & & & & & \\
\hline & & & & TOTAL & 13000 & 9600 \\
\hline
\end{tabular}

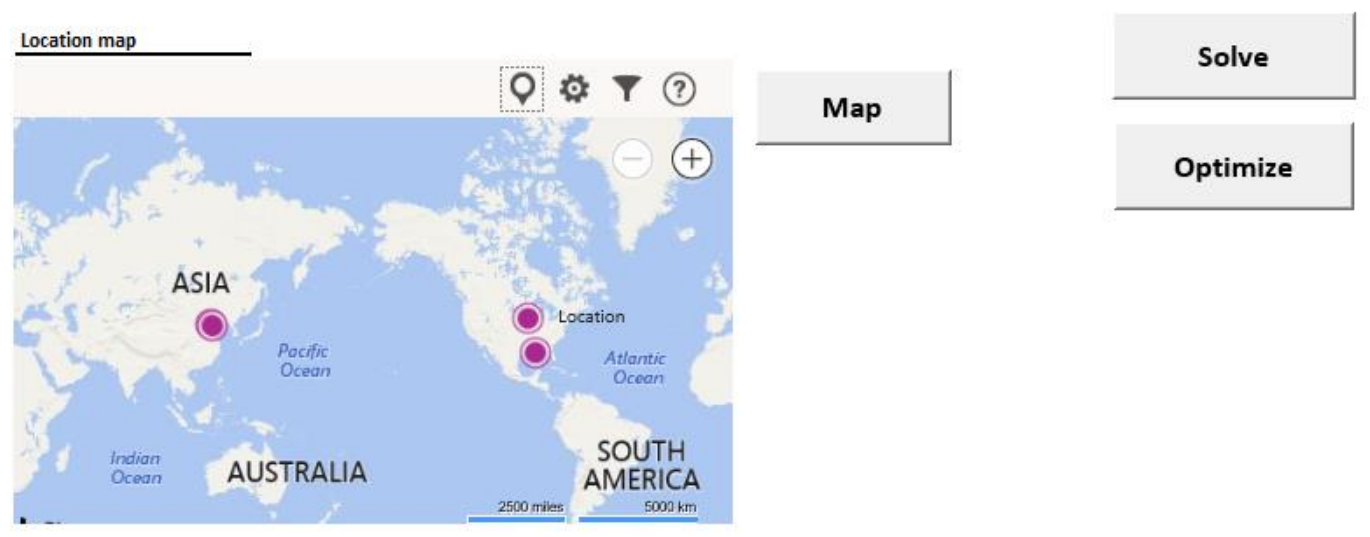

Solve (override)

Figure 13. Software Tool 3 layout

\section{Case Studies Illustrating Software Use}

\subsection{Case 1: Importing Goods - Effects of Varying Origins}

- The term "food miles" was founded on the premise that differing origins of food items drastically change the emissions related to transportation.

- This is true to an extent -- while other factors also influence the true lifecycle carbon emissions of a product, the distance traveled by an item does impact the transportation emissions.

- The distance traveled by food is largely dependent on global supply chain trends. Regional specialization has created popular hubs for certain groups of items.

- For example, about $70 \%$ of the fresh apples consumed in Iowa were from out-of-state locations during peak Iowa harvesting season. 
- The top two apple-producing states in the USA were Washington and New York, respectively, with Washington being the top apple contributor to Iowan grocery stores.

- Case study: What effect does a change in origin of a product (such as Iowan apples) have on the resulting transportation emissions?

\subsection{Case 2: Effects of Modes of Travel and Relative Emissions}

- While origin/destination relationships are important to the overall sustainability of product supply chains, the distance between two points is not an end-all factor.

- The effects of differing modes of transportation is often overlooked and/or underestimated. The emissions that result from equivalent routes (in terms of distance and cargo load) with differing methods of transportation can be enormously different.

- One example of this is distant overseas travel. A long-distance cargo plane results in about 50 times the $\mathrm{CO}_{2 \mathrm{eq}}$ emissions of a long-distance ship over the same distance with an equal cargo load.

- Fish is a product that exemplifies this idea well. The production of fresh and frozen fish is extremely similar, but distribution modes must vary to avoid the spoilage of fresh product.

- Case study: What differences can be observed in the modeling of a single route with differing vehicle types?

\subsection{Case 3: Brazil to EU Beef Export Model Comparison (Direct Study Comparison)}

- A wide variety of modeling methods and calculations can be used to estimate vehicle emissions.

- As there are too many factors to true vehicle efficiency to determine a single accepted estimation procedure, "true" emissions values are difficult to confirm.

- There are two primary practices for these cases. The first uses a vehicle emissions factor per unit distance and mass, while the second compares load capacity and fuel consumption with a fuel efficiency factor.

- This study utilizes the second approach to examine both the fiscal and environmental optimizations of the beef trade path between southern Brazil and northwestern Europe (Soysal et al., 2013).

- Case study: How similar are the emissions estimations calculated through different modeling methods?

\subsection{Case 4: Efficiency of International Trade Trends - USA Beef Exchange}

- The USA is the largest importer, largest producer, and second largest exporter of beef products.

- One of the side effects of this standing in beef trade is reciprocal trade, or trade that is back/forth between the same two nations.

- Reciprocal trade is common and often quite harmless between bordering countries - often the trades are just based on the dynamics of varying locations of production hotspots near the border.

- A less common, but much more impactful, kind of reciprocal trade is between distant countries.

- Of these reciprocal trade patterns, the Costa Rican beef exchange was especially notable. Costa Rica imported 27 million pounds of beef from the USA in 2016, but also exported 5 million pounds to the USA in 2016 (USDA ERS, “Cattle,” 2018).

- Case study: What are the environmental effects of reciprocal trade in terms of transportation emissions?

\section{Results}

\subsection{Case 1}

In this case, the effects of differing origins (namely Washington, New York, and Iowa, USA) for Iowan apple consumption was modeled using Tool 2. Although Iowa is a key part of historical apple production, the origin of 
fresh apples at Iowan marketplaces is about $70 \%$ out-of-state during peak harvest times, and $85 \%$ out-of-state in the Iowa apple off-season (Pirog, 1999).

In fall harvest time, one of the top contributors of fresh apples to Iowa is the state of Washington, the top apple-producing state in the USA (Pirog, 1999). While the relationship between a top producer and top contributor may seem obvious, there are some exceptions in Iowan apple sources. New York, a closer state to Iowa, is comparable in growing conditions and is the second largest contributor to national apple production but is not as commonly seen on Iowan grocery shelves (Cornell University, 2016).

Washington is a northwestern state, so the export of apples to midwestern states is environmentally costly. A shift in Iowa apple sourcing from Washington growers to those of slightly closer states could have a quite substantial impact on systematic transportation emissions. While these states are quite distant, both have excellent apple-growing climates. As both are northern states, they have similar growing seasons and production methods, minimizing extraneous factors in comparisons.

The modeled situation is that of a 10\% Iowan market sourcing adjustment from Washington apples to New York apples. Assuming the grocery store stocking mass is proportional to the average apple consumption per capita in the USA (15.3 pounds of fresh apples per year) in the city of Ames with approximately 66,000 people, about 101 thousand pounds (or about 46 tonnes) of Washington apples would be replaced by New York apples in Ames grocery stores over the course of a year (USDA ESMIS, 2012).

The modeling route used for the Washington-Iowa emissions estimation is shown in figure 14. The first portion of the route was travel via semi-truck from Yacoma, WA (the county seat of the top apple-producing county in the state) to Pasco, WA (the location of a major railway station) (USDA ESMIS 2012). Next, a typical rail route was estimated by adding "checkpoints" in Boise, ID and Cheyenne, WY, USA. The mode of travel then switches back to semi-truck from Omaha, NE, USA (another major railway stop) to Ames, IA.

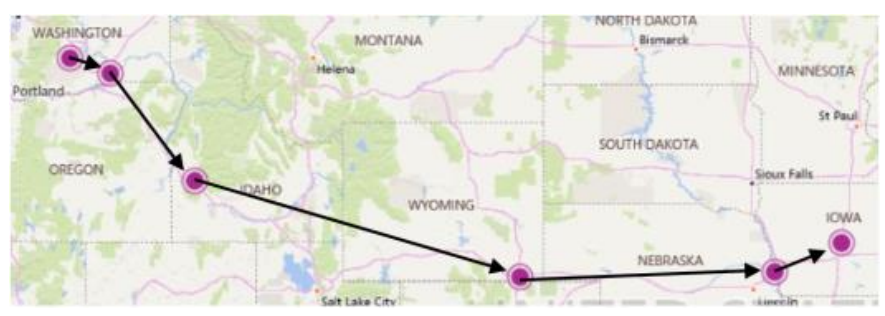

Figure 14. Modele route from Washington to Iowa

The modeling route for New York-Iowa emissions estimation is shown in figure 15. This route was very similar in road/rail proportions to maintain consistency in distance modeling. The origin of the apples was estimated as Rochester, NY, USA. This is also the county seat of a top apple-producing county (Cornell University, 2016). The cargo was then carried via semitruck to Buffalo, NY, USA, where it was loaded onto rail-travel. A "checkpoint" in Cleveland, OH, USA was used to better estimate the path taken by the area railway. The cargo was then switched back to semi travel in Cedar Rapids, IA, USA, after which it was carried to the destination, Ames, IA.

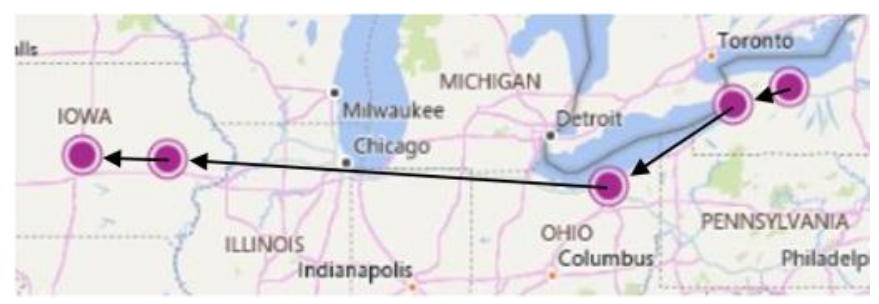

Figure 15. Modeled route from New York to Iowa

Using Tool 2, the carbon emissions of both routes were modeled. The maps were shown to visualize the route and check for inconsistencies with common travel methods. In both modeling scenarios, the cargo load was estimated as 460 tonnes and adjusted to 46 tonnes post-modeling. This was done to better predict the type of mode used in each travel "leg," as it is likely that the shipments would be made with a large mass of other 
products (which would change the mass range used to choose the vehicle emissions rating). It should also be noted that the total distance travelled in the New York-Iowa route was about $1400 \mathrm{~km}$, while the Washington-Iowa route was about $2400 \mathrm{~km}$. The resulting adjusted emissions for the Washington and New York

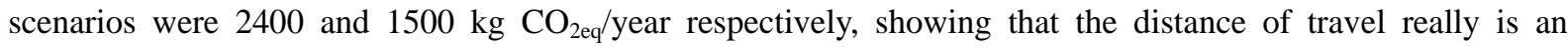
impactful factor in similar scenarios.

\subsection{Case 2}

While distance is the most commonly cited source of emissions disparities, the method by which the goods are transported is potentially more important for route optimization. In the case of American fish consumption, this is a very applicable and easily modeled problem. Overseas fresh fish imports are extremely common and require very inefficient travel routes due to high spoilage risk. While frozen, canned, and otherwise processed fish products may be transported via ocean travel, it is necessary to transport fresh varieties by air, resulting in far greater vehicle emissions factors.

Americans ate about 2.3 pounds of salmon per capita in 2014 (749 million pounds total) (Kantor, 2016). About $80 \%$ of this salmon was imported, with nearly $40 \%$ of salmon imports being fresh (USDA ERS, "Aquaculture," 2018). About $8.4 \%$ of American fresh salmon imports come from the Faroe Islands, the $2^{\text {nd }}$ largest source of fresh imported salmon. Chosen for ease of modeling, the city of Richmond, VA has a population of about 220,000. Assuming average annual salmon consumption and import proportion in this area, about 13,600 pounds (or 6.2 tonnes) of fresh salmon is imported to the city from the Faroe Islands annually (USDA ERS, "Aquaculture," 2018).

Using Tool 2, this was a simple route to model (fig. 16). The intention of this case study was to demonstrate the effect of differing vehicles on total transportation emissions. For the sake of minimizing extraneous factors, two very similar routes have been selected - a "fresh salmon" route and a "frozen salmon" route. The Port of Virginia in Norfolk, VA is one of the top 5 North American ship ports and a common checkpoint for international imports (McCabe, 2017). Similarly, the Richmond, VA airport is the largest airport in the state and handles about 140 million pounds of cargo annually (Richmond International Airport, n.d.).

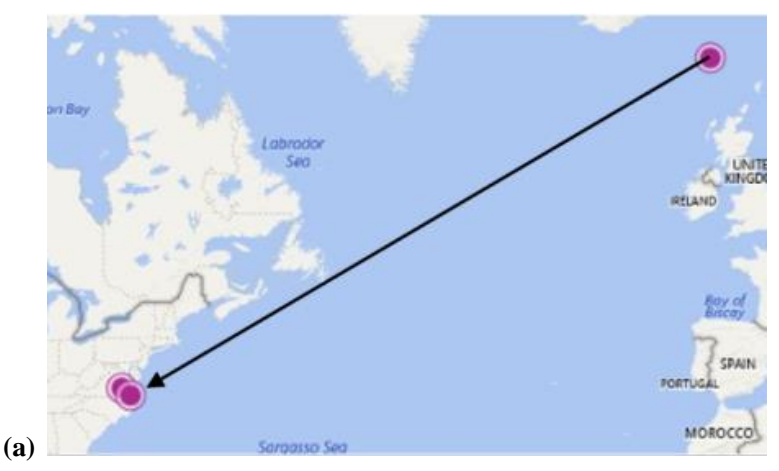

(b)
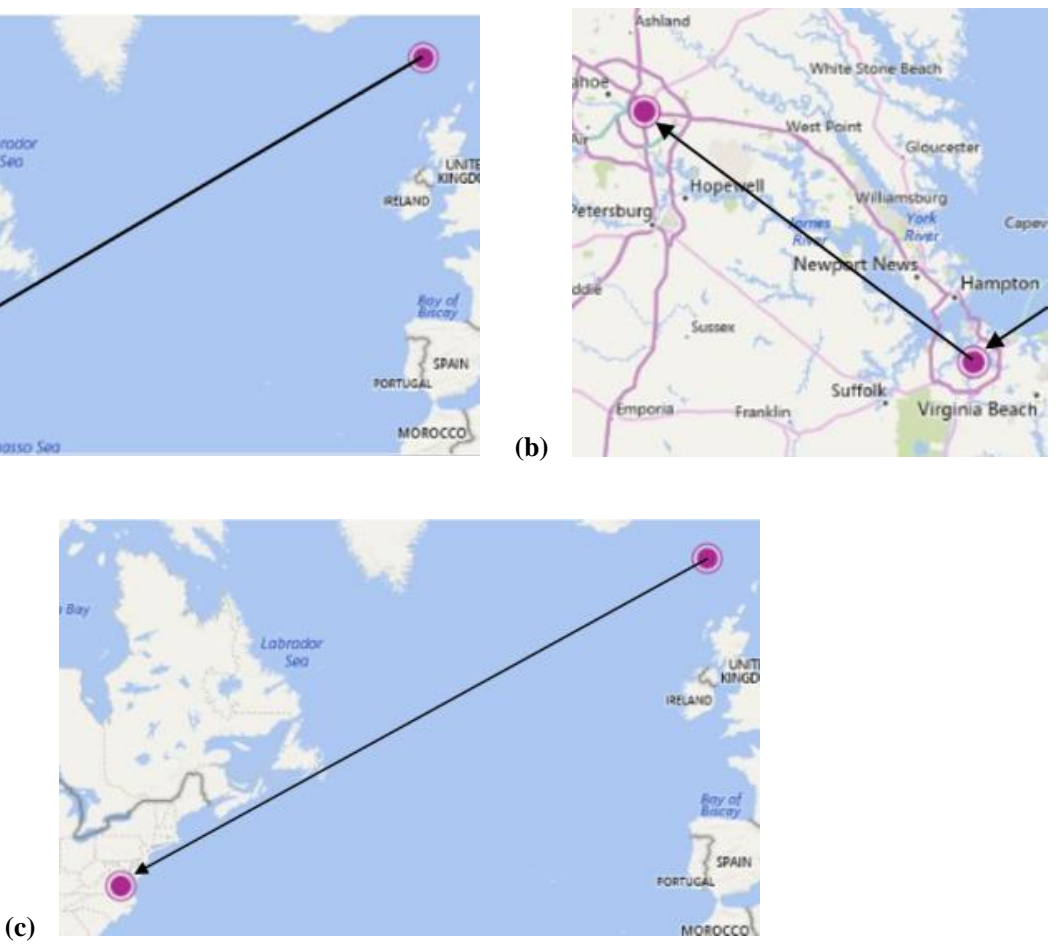

Figure 16. Potential salmon shipping routes through a combination of ship and road travel (shown in (a) and (b), respectively) and through strictly plane travel (c)

These locations lead to two natural freight routes between the origin (the Faroe Islands) and the destination (Richmond, VA). The likely ship cargo route, used for frozen, canned, or processed salmon, would result in ship 
freight from the Faroe Islands to Norfolk, where a truck would likely continue the cargo route to Richmond. In the case of air travel, commonly used for fresh salmon, a plane would carry the salmon from the Faroe Islands to Richmond, where it could be distributed.

When these routes, along with a cargo mass of 6.2 tonnes, were inputted into Tool 2, extremely different emissions values were obtained. In the case of fresh fish transport, the most direct route results in a flight of about $5400 \mathrm{~km}$ from the Vágar airport of the Faroe Islands to the Richmond airport. This flight results in about

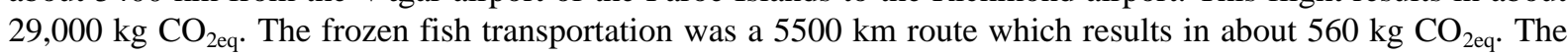
factor of a continental aircraft (the most likely type for this air distance) was 70 times greater than the factor for an ocean watercraft at this distance, leading to this disparity.

\subsection{Case 3}

Differences in reporting and calculations often create a gap in information that is prone to biased exploitation. In order to find a consensus on issues such as the environmental impacts of a product line, it is of great importance to cross-reference and compare the data and methodology of a variety of research projects. A study published by the Operations Research and Logistics Group of Wageningen University examined 18 studies modeling different kinds of transportation emissions to find the distinctions that separate such projects (Soysal et al., 2013). In doing so, they designed a singular-situation modeling program to compare the fiscal and environmental impacts of supply chain changes in Brazilian beef trade.

While the financial and infrastructural research included in that project is compelling and impactful to the overarching emissions problem, the interest of this current study was focused on the comparison of emissions modeling tools. In the research of the Wageningen group, the window of focus was much narrower, bringing higher precision in likely vehicle choices and exact transportation routes. This led to the use of singular averaged fuel efficiency factors (in liters per $\mathrm{km}$ ), estimated for typical road/ocean conditions, truck/ship sizes, and fuel types. This factor was scaled with the load capacity of the truck or ship. Then, the product of the factor, the distance travelled, and a fuel-emissions conversion factor was used to estimate the quantity of $\mathrm{CO}_{2 \mathrm{eq}}$ expelled during travel on a per-vehicle basis.

The route chosen in this study considered the beef exports from a small region - Nova Andradina. The beef produced in this region is likely to be shipped out of Porto de Paranaguá or Porto de Santos and unloaded at either Rotterdam or Hamburg. The exported masses in this scenario were 124 tonnes through Porto de Paranaguá and 676 through Porto de Santos (Soysal et al., 2013). The study assumes equal consumption by both end ports (Rotterdam and Hamburg).

To model a comparable case with our model, the total system was split into four separate routes. First through Port de Santos to Rotterdam, then through Porto de Santos to Hamburg, then through Porto de Paranaguá to Rotterdam, and finally through Porto de Paranaguá to Hamburg, all scaled per the masses and proportions described above (fig. 17). The emissions for these routes were 54,000 $\mathrm{kg} \mathrm{CO}_{2 \mathrm{eq}}, 55,000 \mathrm{~kg} \mathrm{CO}$ 2eq, $9100 \mathrm{~kg} \mathrm{CO}$ 2eq, and $10,000 \mathrm{~kg} \mathrm{CO}{ }_{2 \mathrm{eq}}$, respectively. This led to a total of about $128,000 \mathrm{~kg} \mathrm{CO}_{2 \mathrm{eq}}$.

(a)

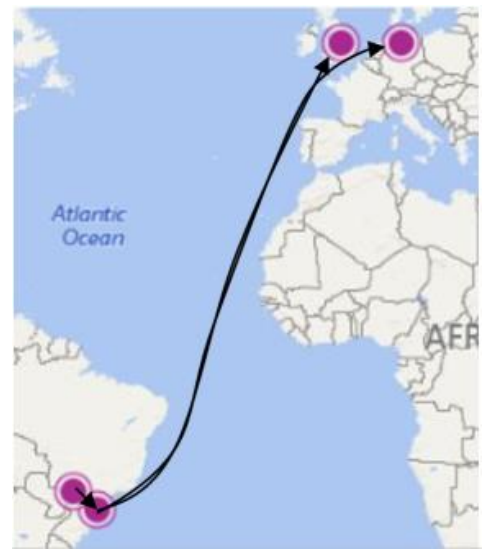

(b)

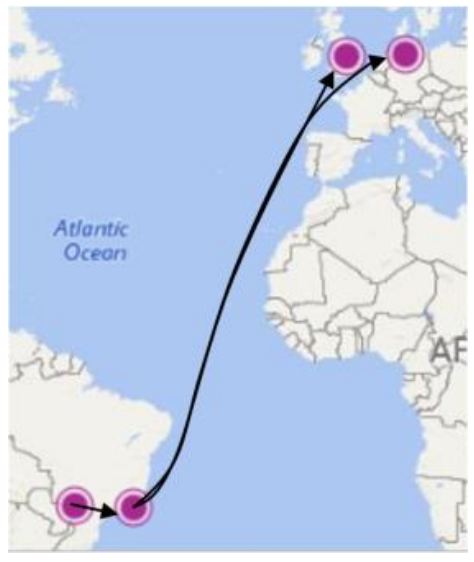

Figure 17. Routes for (a) Porto de Paranquá and (b) Porto de Santos 
The results of our model were very in-line with the estimates from the Wageningen group. The group reported a "lowest cost" emissions value of 127,917 $\mathrm{kg} \mathrm{CO}_{2 \mathrm{eq}}$ and a "lowest emissions" value of 113,633 $\mathrm{kg} \mathrm{CO}_{2 \mathrm{eq}}$ (Soysal et al., 2013). As the vehicle emissions estimations used for this study were from on-road averages, it is expected that our modeled values would be nearest to the lowest cost scenario, which includes $100 \%$ used vehicles and no changes in infrastructure from the current transportation situation (Soysal et al., 2013).

\subsection{Case 4}

Beef supply and demand is of nearly matching quantities in the United States, so it is surprising that international beef trade is a common occurrence. The USA imported 3.0 billion pounds, exported 2.6 billion pounds, produced 25.3 billion pounds, and consumed 25.7 billion pounds of beef (carcass weight) in 2016 (USDA ERS, "Cattle," 2018). Intuitively, one may think that the international exchange of $650 \%$ more beef than required by the production deficit may be the result of trade with the most accessible nations (i.e., bordering countries), but USDA data shows otherwise.

Over half of imports (about 1.8 billion pounds) and over two-thirds of exports (also about 1.8 billion pounds) of processed beef are from/to countries that do not border the USA. From this, around 16 million pounds were purely reciprocal trades between non-bordering countries (USDA ERS, "Cattle," 2018). Of these reciprocal trade patterns, Costa Rican beef exchange was especially notable. Costa Rica imported 27 million pounds of beef from the USA in 2016, but also exported 5 million pounds to the USA in 2016 (USDA ERS, "Cattle," 2018). While it is not entirely clear why this practice is so common for beef products, the environmental impact of such trades is significant.

The case of Costa Rica was chosen for both the demonstration of environmental severity and ease of modeling. As it is a relatively small country, there are two major ports, Puerto Limón on the Atlantic side and Puerto Caldera on the Pacific side. Using Tool 2, both the import and export scenarios of reciprocal trade were modeled. The 5 million pounds (or about 2269 tonnes) of imported beef was estimated as having come from the two major Costa Rican ports. In this model, a baseline estimation of emissions was used to avoid overestimation. Because of this, the model assumed that all product was transported via ship/ferry travel and only includes port-to-port transportation emissions. These routes are shown in figure 18. Although geographically impossible, the "as the crow flies" distances between the closest ship ports were also used. The USA ports were selected on account of their proportion of total USA - Costa Rican import values (compiled from USA Trade Census data), so this modeling situation assumes that beef trade follows the same trading trends as total product trade. As shown below, the model only accounted for $81.5 \%$ of the imports, as the top-eight ports only represented $81.5 \%$ of total USA imports (World Port Source, 2016). Through summing the exports of these eight trade routes, the estimated emissions value for this portion of the case was $88,000 \mathrm{~kg} \mathrm{CO}_{2 \mathrm{eq}}$. If it was assumed that this case was representative of $100 \%$ of the reciprocal imports, the estimate for total reciprocal import emissions would total about $88,000 \mathrm{~kg} \mathrm{CO}$ eq.

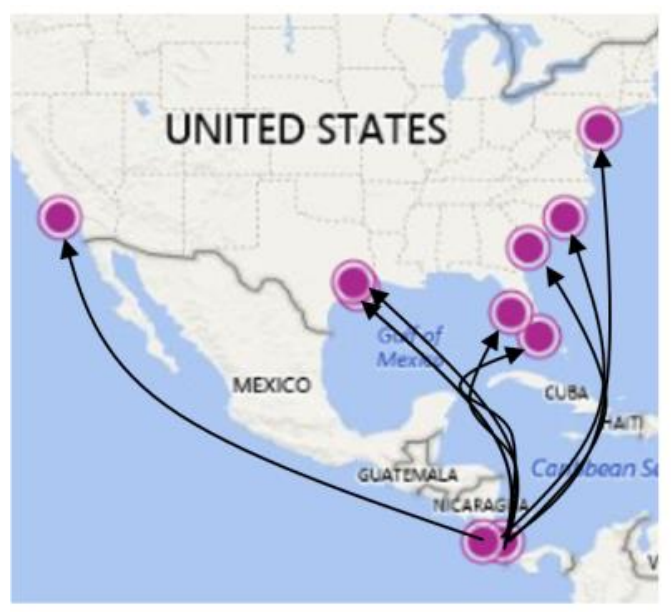

\begin{tabular}{l|r|r|r}
\multicolumn{1}{c|}{ Port } & $\begin{array}{c}\text { Percentage } \\
\text { of Imports }\end{array}$ & $\begin{array}{c}\text { Estimated } \\
\text { Imports } \\
\text { (tonnes) }\end{array}$ & $\begin{array}{l}\text { Estimated } \\
\text { Emissions } \\
\text { (kg CO2e) }\end{array}$ \\
\hline The Port of Wilmingt & 24.2 & 547.9568983 & 29000 \\
\hline Port of Philadelphia & 16.2 & 368.1255527 & 20000 \\
\hline Port Manatee & 12.4 & 280.1961013 & 12000 \\
\hline Port of Miami & 8.6 & 194.3999547 & 7300 \\
\hline Port of Houston & 8.0 & 182.0852884 & 7300 \\
\hline Port of Hueneme & 4.4 & 99.85385312 & 5500 \\
\hline Port of Savannah & 3.9 & 88.65753102 & 3500 \\
\hline Port of Galveston & 3.9 & 87.57607047 & 3400 \\
\hline Total & 81.5 & 1848.85125 & 88000 \\
\hline
\end{tabular}

Figure 18. Beef transportation routes from Brazilian to American ports

The emissions value for the exports to Costa Rica were calculated in the same way. These routes are illustrated in figure 19. To maintain as much consistency as possible, the top 9 ports were used to represent $81.7 \%$ of total 
reciprocal exports (World Port Source, 2016). The lowest possible emissions modeling methods were used for this model as well. Through the estimation of the export routes shown below, about $70,800 \mathrm{~kg} \mathrm{CO}_{2 e q}$ result from the modeled $81.7 \%$ of USA - Costa Rican reciprocal beef exports. Extrapolated to include $100 \%$ of reciprocal beef exports, this would total about $70,800 \mathrm{~kg} \mathrm{CO}_{2 \mathrm{eq}}$.

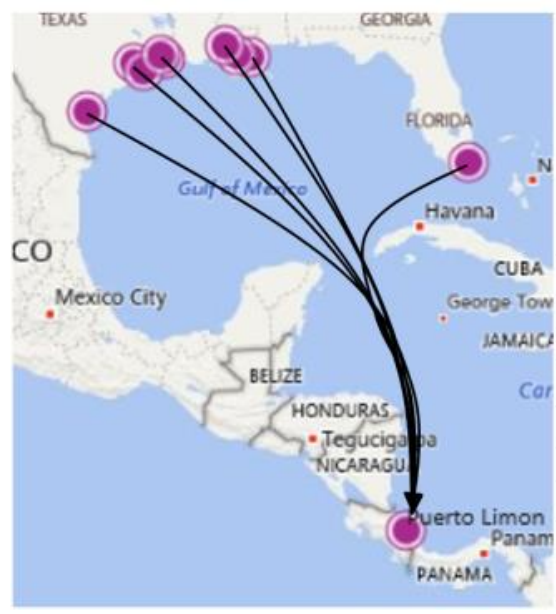

\begin{tabular}{l|r|r|r}
\multicolumn{1}{c|}{ Port } & $\begin{array}{c}\text { Percentage } \\
\text { of Exports }\end{array}$ & $\begin{array}{c}\text { Estimated } \\
\text { Exports } \\
\text { (tonnes) }\end{array}$ & $\begin{array}{l}\text { Estimated } \\
\text { Emissions } \\
\text { (kg CO2e) }\end{array}$ \\
\hline Port of Corpus Christ & 24.0 & 545.3396107 & 21000 \\
\hline Port of New Orleans & 21.5 & 487.8627555 & 18000 \\
\hline Port of Houston & 8.0 & 181.9390531 & 7300 \\
\hline Port of Texas City & 6.1 & 139.3868614 & 5400 \\
\hline Port of Gramercy & 5.9 & 132.9922527 & 5000 \\
\hline Port of Greater Bator & 5.1 & 114.9412961 & 4400 \\
\hline Port of Port Arthur & 4.4 & 99.20854075 & 3900 \\
\hline Port of Beaumont & 3.8 & 86.50162839 & 3400 \\
\hline Port of Miami & 2.9 & 65.28232066 & 2400 \\
\hline Total & 81.7 & 1853.454319 & 70800 \\
\hline
\end{tabular}

Figure 19. Beef transportation routes from American to Brazilian ports

As these data were derived from the lowest possible estimation, there are several other factors to be considered in this type of trade. First, geographical barriers are very important to non-air travel. The routes modeled here result in lower distances than true routes, as ships in a true transportation scenario would have to avoid the land through which the modeled routes pass ("as the crow flies"). Another consideration is that a significant portion of transportation emissions are the result of land travel. Transportation from producer to processor and from processor to port require much less direct routing and use either truck or train travel - both of which have larger emissions factors than ship travel. Lastly, this was also a low assumption because it was assuming all beef product was transported via ship. Some products may use air travel, resulting in far greater emissions.

In total, the reciprocal trade trends of the USA and Costa Rica result in an estimated emission value of at least $158,000 \mathrm{~kg} \mathrm{CO}_{2 \text { eq }}$ per year. When all the effects of this reciprocal trade are summed, the actual impact of these trends are much larger than this model shows. While economic and political incentives often drive this sort of non-bordering trade, observing the true environmental impacts of current practices reveals a great need for more sustainable trade tactics.

\section{Discussion}

\subsection{Other Emissions Factors}

Food trade trends depend heavily on a variety of factors. Spoilage, taste, consumer preference, political influences, regional climates, and economic incentives all impact the travelled routes of food items before reaching the consumer's plate. While the tools developed in this study have the capability of modeling the primary steps of transportation in the life cycle of food products, the total lifecycle of these goods (i.e., cradle-to-grave) have a variety of factors that were not addressed by this modeling system. The first, and possibly most obvious, source of emissions from food products are the actual agricultural production and processing stages. This is indirectly related to food transportation but is categorically separate from the issues of the transportation sector. Another source of emissions - possibly the most underrated - is the portion of the transportation chain that takes the food from its point of sale to the door of the consumer. Last-step LDV transportation emissions were not accurately modeled through the tools in this study, but are an important part of the total supply chain; these have been estimated to result in perhaps double the emissions of products direct-delivered via HDV (Wygonik \& Goodchild, 2012).

The biggest drive for international product transportation is regional specialization. It is generally more efficient for an area to excel at the production of one item (or a few) and then engage in foreign trade than it is for an area to self-sustain. Environmentally, this concept is still applicable. While locally-sourced items may cut transportation emissions, often these emissions act as a sort of "red herring" in the grand scheme of sustainability. 
The life cycle analysis (LCA) of food products contain so much more than what happens after the food is produced. In the case of sourcing problems, one key factor is the environment of the consumer area. Crop growth requires much more use of resources and subsequently creates a much larger carbon footprints. A study on tomato growth published by the French National Institute for Agricultural Research exemplified this well. When comparing the environmental impact of locally-grown tomatoes in Austria with imported Spanish tomatoes, transportation was found to be relatively unimportant in the comparison of total emissions. Overall, the LCA of conventional, multi-tunnel greenhouse tomatoes in Spain resulted in about half the $\mathrm{CO}_{2 \mathrm{eq}}$ emissions of the Austrian-grown conventional, greenhouse tomatoes (Theurl et al., 2013). While the transportation was the largest source of emissions in the lifecycle of the Spanish tomatoes, the Austrian greenhouse's heating requirement resulted in about double the emissions - greatly overshadowing any advantage that the locally-grown tomatoes had vis-à-vis the transportation sector (Theurl et al., 2013).

Production regionalization, however, creates problems when the transportation of fresh food is demanded. A Ghent University study observing food perceptions in Europe found that fresh fish products were thought to be significantly healthier than frozen varieties in every country studied (Vanhonacker et al., 2013). While there wasn't scientific support behind this idea, the perception is still a driving factor in the fish market. This is often at the expense of supply chain sustainability, as never-frozen fish requires quick (and environmentally costly) transportation methods. In cases like these, air travel is common, which greatly increases the emissions resulting from the route. One example of this was described in a study on carbon emissions of Australian seafood exports. Australia transports about 10\% of total seafood exports via air travel (Farmery et al., 2015). Most of this seafood is flighted due to risk of spoilage for fresh fillets. In the case of salmon, the transportation of frozen fillets to the USA via sea expends about $0.7 \mathrm{~kg} \mathrm{CO}_{2 \mathrm{eq}}$ per $\mathrm{kg}$. The air travel required for fresh fillets, on the other hand, expends $18.3 \mathrm{~kg} \mathrm{CO}_{2 \text { eq }}$ per $\mathrm{kg}$ fish for the same route, which is about 9 times the total carbon emissions for farming and processing combined (Farmery et al., 2015). Even if the demand for freshness is maintained, there are alternatives to $100 \%$ air travel. By altering routes to introduce air-sea combination routes (where the food is only flown part of the way), the food could still reach its destination without spoiling while greatly reducing the emissions of the transport (Sims, et al., 2014).

Even for the cases of foods that do not require overseas travel, the modes of transportation contain variances that are hidden upon first observation. For the trucking and heavy-duty vehicle (HDV) options, replacement by rail travel would greatly cut emissions. The International Energy Agency predicts that a 35\% replacement of HDV freight by rail freight would cut global freight emissions by $16 \%$ (Sims, et al., 2014). However, updating to rail travel is not always a simple process. For example, the railways of many areas are inflexible and difficult to expand, hindering the growth of the rail sector. The European Commission has a set goal of using only water or rail vehicles for all freight travel over $300 \mathrm{~km}$ (Sims, et al., 2014). While this would be an effective way to cut transportation emissions over time, the immediate fiscal and environmental cost of infrastructure production and installation would be great. It was estimated that the European rail system would have to double to accommodate this change, requiring a tremendous resource allotment to a network that is slow and costly to replace and improve.

Technology evolution, however, is not such a slow process in most other transport modes. HDV travel is the most easily and consistently improved mode of travel. Due to the shorter lifecycle of road vehicles, replacement is high. This means that outdated vehicles are not as common on road routes as on the routes of other modes. It is much more difficult and costly to replace airplanes, ships, and trains, so HDVs are a more popular target for technological improvement. While trains and ships are currently a more sustainable transportation method, trucks may begin to close the gap with focused vehicle emissions advancements and regulations.

These technological advancements are often the product of outside incentives. Inciting change is not an easy process and requires a great deal of coaxing when the fiscal benefits are hidden or non-existent. Often, governmental regulation is one of the only ways to push for development of vehicles. The immediate investment of such improvements is daunting to customers of the products, hindering the demand for more sustainable choices. Fiscal and governmental pulls have a clear history of polarizing perceptions of certain subjects including sustainability and green initiatives. Without creating some sort of demand for greener products in the market, change can be controversial and slow.

\subsection{Applications}

The intended use of this software was to provide engineers, designers, and planners with a program to model transportation routes. Greater insights in product routing can help supply-chain engineers utilize the "low-hanging fruit" of addressing sourcing inefficiencies, and to greatly decrease greenhouse gas emissions in 
the transportation sector. As exemplified in the case studies discussed above, these tools can help provide some guidance and insights on a wide variety of cases and questions. If used properly, this program could provide a simple and quick way to model many routes of travel to find the most sustainable (and feasible) method of product sourcing.

\subsection{Uncertainty}

All estimates provided by the program contain a great deal of uncertainty. The program was intended to model transportation routes for emissions comparisons, so the numbers and figures given were approximate calculations, not actual measured values. The emissions ratings for the modes of travel were averages of the most typical travel characteristics (more about this can be found in the discussion of data acquisition and at the Network for Transport Measures). The distances were all calculated "as the crow flies," so the actual transportation paths may add distance (and thus emissions) due to indirect routing.

Uncertainties may also arise from user error. Although Tools 2 and 3 were programmed to prevent Train/Rail and Truck/Road travel across oceans, the code will not always prevent unlikely or impossible routes. There were also no features in place to prevent Ship/Ferry travel across land (to allow for possible river routes). The maps on the tools were provided to help visualize any errors that may occur due to the geography of the regions.

The override buttons available in the tools may be used to troubleshoot when the error-checking boundaries prevent likely or necessary travel. These extraneous functions run the program with lowered error-checking, allowing for more travel routes. It is recommended, however, to utilize the mapping functions to determine whether there is a possible routing error before overriding.

\subsection{Future Developments}

As discussed in the section of extraneous emissions factors, transportation is a multifaceted issue. There is an abundance of functions and considerations that could be added to create a more useful and comprehensive software program.

First, the porting options in Tool 3 were not expansive enough to make the optimization function effective in low-population areas. The top world freight ports are often not food-focused and do not include many of the potential food ports in Central/South America which are large contributors to global agriculture. Expanding the selectable and suggested options in Tool 3 would help make more informed decisions about more realistic food transportation routes.

Second, the store-to-home step of transportation is a very important part of emissions modeling. This variable in food supply is one of the most impactful and most easily altered parts of the total lifecycle emissions scheme. Providing a way to model and compare mass delivery systems with personal consumer vehicle use could provide a great deal of insight on an unclear emissions source. This would require the addition of LDVs to the list of transport modes.

Another key feature that could possibly be integrated into future iterations of this set of software tools are time -dependent functions. Perishability is a key consideration in fresh foods and a time estimation function added to the second and third tools would help the user consider the possibility of routes from a spoilage perspective. The added emissions factors of refrigerated trucks would also aid in modeling transportation of perishables. Reflecting those factors in the tools would create a simpler way to measure the feasibility as well as a more accurate measure of emissions.

\section{Conclusions}

Transportation sustainability is a multifaceted problem. Economic, political, and regional (such as specialization and climate) factors all play important roles in how countries import and export goods. Nearly all foods, regardless of origin, are now quite easily accessible, often resulting in less-than-optimal transportation practices. The set of tools described in this study helped examine these issues more closely, giving insight into variations in transportation practices that could potentially help reduce carbon footprints.

These tools have a variety of functions and purposes, but all have common categories of inputs/outputs. In each, the user must either give locational or distance data, which was interpreted as a distance between points. The cargo mass was also an essential factor to the emissions results. Lastly, the user usually needs to give a mode of transportation order, which was used (along with the distance and mass) to determine the specific emissions factor used on the route. This distance, mass, and factor are multiplied to yield an emissions product in $\mathrm{kg} \mathrm{CO}_{2 \mathrm{eq}}$. These tools use an Excel file format to maintain simplicity and provide an easily understood form of emissions modeling for those that wish to find an estimate of currently practiced transportation routes. 
The case studies provided here exemplify the variety of uses for these tools. Estimating the LCA of various products and finding inefficiencies in current practices are two of the most prominent possible uses. As shown in Cases 2 and 3, there are many factors that directly impact transportation emissions. Although distance (or "food miles") can contribute greatly to the total emissions, the modes by which these distances are travelled leave an equally large footprint. A change in origin of Iowan apples from the state of Washington to the state of New York resulted in a reduction of carbon emissions that was roughly proportional to the change in route distance (about $37 \%$ ). However, the modeled salmon transportation route from the Faroe Islands (America's 2nd largest source of imported fresh salmon) to Richmond, VA resulted in a roughly 98\% reduction of emissions when shipped via sea rather than flown, even though the flown route was slightly shorter in distance. The validity of these tools has been strengthened through comparison to a similar case study. That study, involving an emissions estimation for Brazilian beef transportation by Wageningen University, used an estimation method that compiled methods from 18 other transportation emissions projects. The comparison of the use of these tools with their final estimation resulted in a $1-11 \%$ disparity in results, depending on the method used by the Wageningen University group. This helped confirm that the emissions factors used in our tools were close to the methods and factors used in other literature. In Case 4, transportation optimization was observed. The reciprocal trade pattern of beef between Costa Rica and the United States was analyzed and found to result in at least 158,000 $\mathrm{kg}$ of excess $\mathrm{CO}_{2 \mathrm{eq}}$ annually.

Although these tools do help model one portion of the life cycle of a food product, users must be advised that transportation itself is not an end-all solution to food sustainability. Many other factors play into both the transportation sector as well as the other parts of a product lifecycle. The last portion of transportation, store-to-consumer, was not covered by this modeling program, which may lead to the underestimation of true emissions. Where and how food is produced both directly impact total emissions and indirectly affect transportation choices. Foods produced in a nearby unnatural environment requiring heat input are likely to result in more emissions from production alone than the emissions from the total lifecycle of a product from a distant natural environment. Infrastructure and the manufacturing and maintenance of vehicles also play a role in total transportation lifecycle emissions. Although trains and ships still result in less emissions, trucks are easier to replace with new technologies, speeding the potential for improvements.

Transportation emission reductions are one of the many ways that societies could help limit the rise of global carbon emissions. The food sector, driven by the globalization of the food economy, has created a rising environmental impact due to food transportation. The tools outlined in this study provides a variety of methods for users to analyze and model these transportation systems. While there are many considerable factors in the total lifecycle sustainability of an item, modeling feasible food transportation routes is clearly a step towards lessening the impacts of food transportation emissions.

\section{References}

Barkan, C. (2012). Introduction to Rail Transportation. University of Illinois at Urbana-Champaign. Retrieved from https://web.engr.uky.edu/ jrose/papers/REES\%202012\%20Introduction.pdf

Cooper, D., \& Gustafsson, T. (2004). Methodology for calculating emissions from ships. Swedish Methodology for Environmental Data. Retrieved from https://www.diva-portal.org/smash/get/diva2:1117198/FULLTEXT01.pdf

Cornell University. (2016). New York State Apple Crop Survey Report. Retrieved from https://rvpadmin.cce.cornell.edu/uploads/doc_477.pdf

EPA. (2018). Sources of Greenhouse Gas Emissions. Retrieved from https://www.epa.gov/ghgemissions/sources-greenhouse-gas-emissions

Farmery, A. K., Gardner, C., Green, B. S., Jennings, S., \& Watson, R. A. (2015). Domestic or imported? An assessment of carbon footprints and sustainability of seafood consumed in Australia. Environmental Science \& Policy, 54, 35-43. https://doi.org/10.1016/j.envsci.2015.06.007

Hausberger, S., Rexeis, M., Zallinger, M., \& Luz, R. (2009). Emission Factors from the Model PHEM for the HBEFA Version 3. Institute for Internal Combustion Engines and Thermodynamics. Retrieved from http://www.hbefa.net/e/documents/HBEFA_31_Docu_hot_emissionfactors_PC_LCV_HDV.pdf

Iowa DOT. (2016). Iowa State Railroad Map. Retrieved from https://iowadot.gov/iowarail/railroads/maps/basemap.pdf

Kantor, L. (2016). Americans' Seafood Consumption Below Recommendations. USDA. Retrieved from https://www.ers.usda.gov/amber-waves/2016/october/americans-seafood-consumption-below-recommendat 
ions/

McCabe, R. (2017). Port of Virginia now ranks among top 5 biggest ports in North America. Retrieved from https://pilotonline.com/business/ports-rail/article_03bcd78a-f714-5249-867d-4e5c226ba93d.html

Mooney, C. (2015). The Magic Number. Retrieved from http://www.washingtonpost.com/sf/national/2015/11/29/carbon/?utm_term=.6b71b01e9a82

NTMCalc 4.0. (n.d.). Network for Transport Measures. Retrieved from https://www.transportmeasures.org/ntmcalc/v4/basic/index.html\#/

Pirog, R. S. (1999). Comparing Apples to Apples: An Iowa Perspective on Apples and Local Food Systems. Leopold Center Pubs and Papers, 1. Retrieved from https://lib.dr.iastate.edu/cgi/viewcontent.cgi?article=1001\&context=leopold_pubspapers

Richmond International Airport. (n.d.). Air Cargo. Retrieved from https:/flyrichmond.com/air-cargo/

Sims R., Schaeffer, R., Creutzig, F., Cruz-Núñez, X., D’Agosto, M., Dimitriu, D., ... Tiwari, G. (2014). Climate Change 2014: Mitigation of Climate Change: Contribution of Working Group III to the Fifth Assessment Report of the Intergovernmental Panel on Climate Change. Cambridge, United Kingdom: Cambridge University Press. Retrieved from https://www.ipcc.ch/pdf/assessment-report/ar5/wg3/ipcc_wg3_ar5_chapter8.pdf

Soysal, M., Bloemhof-Ruwaard, J., \& Van der Vorst, J. (2013). Modelling food logistics networks with emission considerations: The case of an international beef supply chain. International Journal of Production Economic, 152, 57-70. https://doi.org/10.1016/j.ijpe.2013.12.012

Theurl, M. C., Haberl, H., Erb, K.-H., \& Lindenthal, T. (2014). Contrasted greenhouse gas emissions from local versus long-range tomato production. Agronomy for Sustainable Development, 34(3), 593-602. https://doi.org/10.1007/s13593-013-0171-8

US DOT. (n.d.). Freight Rail Overview. Retrieved from https://www.fra.dot.gov/Page/P0362\#WhereFreightMoves

USDA ERS. (2018). Aquaculture Data. Retrieved from https://www.ers.usda.gov/data-products/aquaculture-data/

USDA ERS. (2018). Cattle \& Beef. Retrieved from https://www.ers.usda.gov/topics/animal-products/cattle-beef/

USDA ESMIS. (2012). Apple Statistics. Retrieved from http://usda.mannlib.cornell.edu/MannUsda/viewDocumentInfo.do?documentID=1825

Vanhonacker, F., Pieniak, Z., \& Verbeke, W. (2013). European consumer perceptions and barriers for fresh, frozen, preserved and ready-meal fish products. https://doi.org/10.1108/00070701311317810

Washington State DOT. (2017). Washington State Freight System Plan. Retrieved from http://www.wsdot.wa.gov/publications/fulltext/freight/Freight-Plan-2017SystemPlan.pdf

World Port Source (2016). USA Foreign Trade with Costa Rica. Retrieved from http://www.worldportsource.com/trade/CRI.php

Wygonik, E., \& Goodchild, A. (2012). Evaluating the Efficacy of Shared-use Vehicles for Reducing Greenhouse Gas Emissions: A U.S. Case Study of Grocery Delivery. Journal of the Transportation Research Forum, 51, 111-126. https://doi.org/10.5399/osu/jtrf.51.2.2926

\section{Appendix: MS Excel Program and Instructions for Use}

The authors provide their MS Excel program for those readers who are interested in modeling various transport distances for a variety of food products for their specific situations of interest. The user may either run the MS Excel directly, or they can modify the programming for their specific modeling needs. This file can be downloaded (Tools.coded.xlsm) from the authors' online GitHub repository, available at: https://github.com/karosent/Food_Transport_Emissions. The reader is encouraged to work with this file in order to more fully explore the simulation's capabilities.

If the reader utilizes the authors' online GitHub repository to access the MS Excel program, they will be provided with instructions which are available as a README.pdf file on the GitHub site.

\section{Copyrights}

Copyright for this article is retained by the author(s), with first publication rights granted to the journal.

This is an open-access article distributed under the terms and conditions of the Creative Commons Attribution license (http://creativecommons.org/licenses/by/4.0/). 